\title{
The Influence of Life Events on Mental Health of Chinese College Students
}

\author{
Yingshan Bao ${ }^{1, a}$, Fangwei Zhu', b and Yue $\mathrm{Hu}^{2, \mathrm{c}}$ \\ ${ }^{1}$ Faculty of Management and Economics, Dalian University of Technology, Dalian 16024, China; \\ ${ }^{2}$ Psychological Health Education and Consultation Center, Dalian University of Technology, Dalian \\ 116024, China \\ abaoys@dlut.edu.cn, bzhufw@dlut.edu.cn, chuyue405@163.com
}

Keywords: Self-Efficacy; Life Events; Mental Health; Mediator Effects.

\begin{abstract}
Objective: This research aims to explore the relationship between Chinese college students' life events, self-efficacy and mental health. Methods: 524 undergraduates were measured with Adolescent Self-Rating Life Events Questionnaire (ASLEC), General Self-Efficacy Scale (GSES), and Symptom Checklist 90 (SCL-90). Results: Correlation analysis shows significant negative correlation between life events and self-efficacy; life events have a significant negative correlation with mental health, and self-efficacy has a significant positive correlation. Analysis of variance shows low self-efficacy students scored higher than students of high self-efficacy group in life events such as interpersonal relationship, course study pressure, penalty and loss; high self-efficacy students scored higher in the somatization of mental health, obsessive-compulsive symptoms, interpersonal sensitivity, depression, paranoia, psychosis and other mental health problem. With the mediator effects analysis, self-efficacy is a partial mediator variable between life events and mental health. Conclusion: Life events can predict the mental health of college students both directly and indirectly through its impact on self-efficacy, thus, self-efficacy can be used to intervened college students' mental health.
\end{abstract}

\section{Introduction}

Life events have a significant influence on mental health [1-4], however, whether life events can cause mental health problems or not, one side depends on the attributes of life events itself, and the other side is dependent on high and low of individual self-efficacy to a large extent. Self-efficacy is that the individual dominate or control own actions, which reflects the individual confidence and ability to take appropriate action faced environmental challenges. Previous research have shown that there is a significantly positive correlation between self-efficacy and college students' mental health, self- efficacy can play a prediction role in mental health of college students. Students with a relatively high level of self-efficacy tend to be easy and happy to take part in various activities, but students with a relatively low level of self-efficacy are more likely to emphasize their incompetence and difficulties in learning, and the incidence of external things is ascribed to internal causes, thus resulting in anxiety, depression and other psychological problems. Therefore, this research explores the relationship between college students' life events and mental health and the role of self-efficacy through correlation analysis, variance analysis and regression analysis methods.

\section{Objects and Methods}

\subsection{Subjects.}

548 undergraduates from four universities are carried out questionnaire by the method of stratified random sampling in Dalian, China. The spot testing are used and questionnaire are recycled, a total of 524 questionnaires were collected, the effective recovery rate is $95.62 \%$, including 295 boys, 229 girls, the age are between 18 and 25 . 


\subsection{Instrument.}

\subsubsection{Adolescent Self-Rating Life Events Questionnaire (ASLEC)}

The scale was compiled by Liu Xianchen in 1997, including 27 items, mainly interpersonal relationship, learning stress, loss, health adaptation, punishment, others six dimensions. The 5-level assessment are used, nearly 12 months of psychological feelings are surveyed, the higher the score, the more life events.

\subsubsection{Symptom Checklist 90 (SCL-90)}

The scale includes 90 items, including somatization, force symptom, interpersonal sensitivity and so on, nine dimensions. 5-level assessment is used to scored, the higher the score, the higher contained symptom level; the scale has been proved to have good reliability and validity.

\subsubsection{General Self - Efficacy Scale (GSES)}

The scale was revised by Zhang and Schwarzer in 1995 [5], there are a total of 10 clauses, 4-level assessment are used to scored. The higher the total score, the more the self-efficacy.

\section{The Result}

\subsection{The correlation among life events, self-efficacy and mental health}

The life events, self-efficacy and mental health are carried out pear-son correlation analysis, the results are shown in Table 1. There are significant correlations among life events, self-efficacy, mental health; college students' life events, self-efficacy, and mental health all show a significantly negative correlation; there are significantly positive correlation in self-efficacy and mental health of the college students.

Table 1. The correlation among life events, self-efficacy and mental health

\begin{tabular}{|c|c|c|}
\hline & life events & self-efficacy \\
\hline life events & & \\
\hline self-efficacy & $-0.256^{* *}$ & $0.234^{* *}$ \\
\hline mental health & $-0.635^{* *}$ & \\
\hline
\end{tabular}

Note: $* \mathrm{p}<0.05, * * \mathrm{p}<0.01$, the same as below.

\subsection{The comparative analysis of self-efficacy level difference and life events}

In a ratio of $27 \%$ to $33 \%$, the college students' self-efficacy are divided into high self-efficacy and low self-efficacy group, compare differences in life events of the two, and the results are shown in Table 2. The interpersonal relationships, learning pressure, punishment, loss, others, and overall dimensions in life events, the scores of low self-efficacy group are higher than high score group, difference have statistical significance; the scores of low self-efficacy group are higher than high self-efficacy group in healthy adaptation,, but difference is no statistically significant.

Table 2. The difference comparison of high and low self-efficacy group in life events $(\mathrm{M}+/-\mathrm{SD})$

\begin{tabular}{|c|c|c|c|}
\hline & low self-efficacy group & high self-efficacy group & \\
\hline & $(\mathrm{n}=142)$ & $(\mathrm{n}=141)$ & $\mathrm{t}$ \\
\hline $\begin{array}{c}\text { interpersonal } \\
\text { relationships }\end{array}$ & $7.45 \pm 3.77$ & $4.88 \pm 3.16$ & $3.370^{* *}$ \\
\hline learning pressure & $8.31 \pm 2.94$ & $5.24 \pm 3.25$ & $4.504 * *$ \\
\hline punishment & $5.05 \pm 3.94$ & $2.22 \pm 2.42$ & $3.950^{* *}$ \\
\hline loss & $5.36 \pm 3.29$ & $3.29 \pm 2.54$ & $3.204 * *$ \\
\hline healthy adaptation & $2.69 \pm 2.65$ & $1.80 \pm 1.75$ & 1.790 \\
\hline others & $3.00 \pm 3.0$ & $1.51 \pm 1.58$ & $2.820^{* *}$ \\
\hline total score & $31.86 \pm 14.60$ & $18.95 \pm 11.30$ & $4.495 * *$ \\
\hline
\end{tabular}




\subsection{The comparative analysis of self-efficacy level differences and mental health}

In a ratio of $27 \%$ to $33 \%$, the college students' self-efficacy are divided into high self-efficacy and low self-efficacy group, compared with the differences of the two in mental health, the results are shown in Table 3. The somatization of mental health, obsessive-compulsive symptom, interpersonal sensitivity, depression, hostility, terror, paranoia, psychiatric and mental health score each dimension, the scores of low self-efficacy group are higher than high self-efficacy group, and the difference is statistically significant; but scores of low self-efficacy group are higher than high self-efficacy group in the anxiety dimension, but difference is no statistically significant.

Table 3. The difference comparison of high and low self-efficacy group in the mental health $(\mathrm{M}+/-$

$\mathrm{SD})$

\begin{tabular}{|c|c|c|c|}
\hline & $\begin{array}{c}\text { low self-efficacy group } \\
(\mathrm{n}=142)\end{array}$ & $\begin{array}{c}\text { high self-efficacy group } \\
(\mathrm{n}=141)\end{array}$ & $\mathrm{t}$ \\
\hline somatization & $1.10 \pm 0.18$ & $1.02 \pm 0.06$ & $2.64^{* *}$ \\
\hline obsessive-compulsive symptom & $1.44 \pm 0.39$ & $1.15 \pm 0.18$ & $4.35^{* *}$ \\
\hline interpersonal sensitivity & $1.21 \pm 0.25$ & $1.08 \pm 0.21$ & $2.46^{*}$ \\
\hline depression & $1.15 \pm 0.19$ & $1.03 \pm 0.06$ & $3.93^{* *}$ \\
\hline anxiety & $1.16 \pm 0.17$ & $1.11 \pm 0.14$ & 1.56 \\
\hline hostility & $1.14 \pm 0.23$ & $1.05 \pm 0.14$ & $2.17^{*}$ \\
\hline terror & $1.09 \pm 0.21$ & $1.02 \pm 0.07$ & $2.06^{*}$ \\
\hline paranoia & $1.14 \pm 0.16$ & $1.08 \pm 0.14$ & $1.63^{* *}$ \\
\hline psychiatric & $1.16 \pm 0.20$ & $1.08 \pm 0.13$ & $2.20^{*}$ \\
\hline others & $1.16 \pm 0.19$ & $1.07 \pm 0.16$ & $2.28^{*}$ \\
\hline total score & $106.07 \pm 14.29$ & $96.22 \pm 8.04$ & $3.88^{* *}$ \\
\hline
\end{tabular}

\subsection{The intermediary effect validation of self-efficacy in the life events and mental health relationship}

It is known from the correlation analysis of life events, self-efficacy and mental health, there are significant correlations among three variables, and thus the relationship among the three can be further analyzed. Therefore, this research test the relationship among the three by adopting the intermediary effect validation procedures proposed by Wen Zhonglin [6]. The results are shown in Table 4. College students' life events significantly positively predict the mental health level of the individual, add the intermediary variables of self-efficacy, the relationship between college students' life events and mental health has significant changes, therefore, self-efficacy is part intermediary variable between college students' life events and mental health.

Table 4. Intermediary effect test

\begin{tabular}{|c|c|c|}
\hline step & standardized regression equation & regression coefficient test \\
\hline first step & $\mathrm{y} 1=0.635 \mathrm{x}$ & $\mathrm{SE}=0.404 \mathrm{t}=10.109 * * *$ \\
\hline second step & $\mathrm{m}=-0.265 \mathrm{x}$ & $\mathrm{SE}=0.070 \mathrm{t}=-3.373^{* * *}$ \\
\hline \multirow{2}{*}{ third step } & $\mathrm{y} 1=0.616 \mathrm{~m}-0.071 \mathrm{x}$ & $\mathrm{SE}=0.418 \mathrm{t}=9.465 * * *$ \\
& $\mathrm{SE}=0.418 \mathrm{t}=-1.095^{* * *}$ \\
\hline
\end{tabular}

\section{Conclusion and Discussion}

The research results show that college students' life events and mental health are significantly related, it is found that life events have positive prediction effects on mental health through the regression analysis, it is consistent with a lot of research results $(3,7)$. It shows that the greater the influence of life events on individuals, it is easy to cause the students' psychological problems, reduce the students' psychological health level, it shows that the students groups as the target group in the psychological health education process, should fully consider all kinds of life events impact on the their mental health, and take corresponding measures to reduce the influence of life events. 
In addition, the research found that college students' self-efficacy were significantly associated with the college students' mental health, and life events have partial mediation effect in the process of the mental health influence. The higher the college students' self-efficacy, when face the life events and environmental challenges with more confidence and courage, the better mental health.

Furthermore, there are a close relationship among life events, self-efficacy, and the college students' mental health. Self-efficacy has partial mediation effect in life events effect on mental health influence. That is to say, life events can directly influence the individual psychological health; also can cause indirect influence on individual mental health through self-efficacy.

This research has practical enlightenment significance on the current psychological health education work; on the one hand, college students' psychological health education should give full attention to the impact of life events for students, through improving student life learning environment, reducing the pressure of life events. On the other hand, improvements of students' self-efficacy level are emphasized. At present, the school attaches great importance to the significant event influence on students' mental health, when psychological crisis event happened; schools are able to give timely intervention. Schools should improve and protect students' self-efficacy as more important part of the psychological health education work, actively cultivate students' mental attitude, and adopt a reasonable way to deal with own problems.

\section{Acknowledgments}

This work is supported by Social Science Foundation of Liaoning Province of China L15CSH006 and the Fundamental Research Funds for the Central Universities.

\section{References}

[1]. L. Peng, J. Zhangand M. Li et al. Negative life events and mental health of Chinese medical students: The effect of resilience, personality and social support, Psychiatres. vol. 196(2012) No. 1, p.138-141.

[2]. W. Chen. Self-Concept, Stressful Life Event and Mental Health.Chinese Journal of Clinical Psychology.vol. 5(1997) No. 4, p.212-214.

[3]. Y. J. Zhang.A Path Analysis on Life Events, Negative Automatic Thoughts, Coping Style and Depression. Psychological Development \& Education. vol. 21(2005) No. 1, p.96-99.

[4]. S. Guney, F. Akcaand G. Sahin. The Interrelation between Traumatic Life Events and Mental Health in Turkish University Students, Procedia - Social and Behavioral Sciences. vol.12 (2011) No. 1 2, p.122-125.

[5]. J. X. Zhangand R. Schwarzer. Measuring Optimistic Self-Beliefs - A Chinese Adaptation of the General Self-Efficacy Scale. Psychologia,.vol. 38(1995)No. 3, p.174-181.

[6]. Z. L. Wen, L. Chang, K. T. Hauand H. Y. Liu.Testing and application of the mediating effects. Acta Psychologica Sinica.vol. 36(2004)No. 5, p.614-620.

[7]. L. I. Yong, Xin and G. Zhou. A Cross-lagged Regression Analysis between Life Events and Depression of College Students.Chinese Journal of School Health. vol. 28(2007) No. 1, p.28-29. 